\title{
Fat Grafting with Tissue Liquefaction Technology as an Adjunct to Breast Reconstruction
}

\author{
Utku Dolen $^{1} \cdot$ Justin B. Cohen ${ }^{1} \cdot$ Bo Overschmidt $^{1} \cdot$ Marissa M. Tenenbaum $^{1}$ • \\ Terence M. Myckatyn ${ }^{1}$
}

Received: 9 May 2016/Accepted: 29 August 2016/Published online: 11 August 2016

(C) Springer Science+Business Media New York and International Society of Aesthetic Plastic Surgery 2016

\begin{abstract}
Background Tissue liquefaction technology (TLT) delivers warmed saline from the liposuction cannula tip at low pressure pulses to disaggregate adipocytes. This technology differs significantly from that used in other liposuction devices including water jet-assisted liposuction. Here we introduce our early experience with this technology in the setting of fat transfer for revision breast reconstruction.

Methods A retrospective chart review of 136 consecutive patients who underwent fat harvest with TLT and subsequent transfer into 237 breast reconstructions was conducted at a single institution. This two-surgeon series examined donor and recipient site complication rates over a median follow-up of 143 days [87-233].

Results The overall complication rate was $28.7 \%$, of which the majority $(22.1 \%)$ was fat necrosis at the recipient site as documented by any clinical, imaging, or pathologic evidence. The abdomen served as the donor site for half of the cases. Donor site complications were limited to widespread ecchymosis of the donor site notable in $10.4 \%$ of cases. Twenty-five percent of patients had received postmastectomy radiotherapy prior to fat transfer. Prior to revision with fat transfer, implant-based breast reconstruction was used in $75.5 \%$ of cases, and autologous flaps in the remainder. Fat transfer was combined with other reconstructive procedures $94.1 \%$ of the time.

Conclusions TLT can be used to harvest adipocytes for fat transfer with donor site morbidity and recipient site
\end{abstract}

Terence M. Myckatyn

myckatyn@wudosis.wustl.edu

1 Division of Plastic and Reconstructive Surgery, Washington University School of Medicine, 1040 N. Mason, Ste 124, St Louis, MO 63141, USA complications comparable to other modalities. The efficiency and quality of harvested fat makes this technology appealing for wide spread adoption during fat transfer. Level of Evidence IV This journal requires that the authors assign a level of evidence to each article. For a full description of these Evidence-Based Medicine ratings, please refer to the Table of Contents or the online Instructions to Authors www.springer.com/00266.

Keywords Liposuction - Fat graft - Breast reconstruction · Tissue liquefaction technology $\cdot$ Fat transfer

\section{Introduction}

Autologous fat transfer continues to increase in popularity as a powerful tool to revise the contour of the face, trunk, and extremities. In aesthetic surgery, $85 \%$ of American Society of Plastic Surgeons (ASPS) members now use fat grafting at least some of the time during rhytidectomy [50] and $28 \%$ use fat grafting in aesthetic breast surgery [29]. Fat transfer is also widely utilized in breast reconstruction, where it is employed at least part of the time by $62 \%$ of ASPS membership [54]. The indications for fat transfer have expanded past the face and breasts to include rejuvenation of the hands [14] and lips [15], recontouring of scars [30], gluteal augmentation [55], and penile enlargement [41]. In addition to contour correction or volume augmentation, fat transfer may have a role in ameliorating some of the effects of radiation-induced cutaneous fibrosis [53].

Key to the expanded application of fat transfer for aesthetic and reconstructive indications are its safety, efficacy, and efficiency. Clinical studies suggest that fat transfer is an oncologically safe technique following mastectomy whereby recurrence rates do not statistically significantly differ 
between engrafted and naïve cohorts [16, 42]. By contrast, some clinical data following lumpectomy [42-44] as well as studies in animal and in vitro models suggest that fat transfer may potentiate the malignant behavior of active breast cancer cells. This may be mediated by adipose-derived stem cells or growth factors elaborated by transferred adipocytes [10, 23, 32-34, 37, 48, 60, 61]. These findings require more thorough investigation, particularly in clinically relevant models.

Current literature suggests that the efficacy of fat grafting is highly variable, with graft take ranging from 20 to $80 \%[22,31]$. As a result, plastic surgeons often counsel patients that only half of the transferred fat will engraft. There are multiple disparate factors contributing to optimal conditions for fat graft survival including donor site $[39,56]$, medications utilized in tumescence solution $[17,25]$, aspiration pressure [49], reinjection rate [13, 38], fat harvesting technique [8, 24], and recipient site factors [26-28]. The efficient harvest, processing, and reinjection of fat, while less commonly discussed, are also important for the long-term success of this technique [29]. Shortening the duration that harvested adipocytes reside ex vivo may optimize the proportion remaining viable upon reinjection resulting in better retention and less fat necrosis. Improved efficiency also impacts cost by shortening operative times and minimizing the need for additional fat processing steps that precede reinjection of harvested fat.

We report on the utility of tissue liquefaction technology (TLT; HydraSolve Lipoplasty System; Andrew Technologies, Irvine, CA) to harvest fat for subsequent transfer. Originally developed for cataract surgery in 2003, tissue liquefaction lipoplasty (TLL) selectively liquefies adipose tissue using warmed saline $\left(37-55^{\circ} \mathrm{C}\right)$ delivered in low pressure pulses (300-1100 psi) administered within the liposuction cannula tip. Energy from the device is sufficient to disaggregate adipocytes into $0.5-2.0 \mathrm{~mm}$ clusters while reportedly maintaining the integrity of cell membranes, blood vessels, nerves, and connective tissues. Minimal soft tissue disruption, swelling, pain, heat transfer, and ecchymosis, along with less surgeon fatigue and efficient fat harvest with reduced fibrous tissue in the resulting graft material are suggested advantages of TLL. The following is the first report using TLT to harvest fat for subsequent transfer to the breast for revision following postmastectomy breast reconstruction.

\section{Methods}

\section{Study Sample}

A retrospective chart review of 136 consecutive patients was conducted following approval by our institutional review board (IRB\# 201505068). TLT was used in all subjects to harvest adipocytes for revision fat grafting after previous autologous or implant-based breast reconstruction. Procedures were performed at a single institution from March 2013 to March 2015. Patients whose fat was harvested by any other method or transferred for any reason other than refinement of an ipsilateral breast reconstruction were excluded.

\section{Study Design}

Patient characteristics of interest included age, body mass index (BMI), smoking status, and comorbidities (i.e., diabetes and hypertension). Smoking status was classified into three different groups: patients who never smoked, patients who quit at least 1 month prior to surgery, and current smokers. Adjunctive clinical information included tumor side, type of breast reconstruction (implant based or autologous), donor region for fat harvest, volume of tumescence solution, volume of fat graft injected, duration of surgery, ecchymosis at the donor region, radiotherapy, complications, and follow-up time.

Ecchymosis was classified into three groups: "minimal" which was patchy discoloration $<25 \mathrm{~cm}^{2}$; "moderate" which was continuous discoloration $>25 \mathrm{~cm}^{2}$; and "widespread" which was uniform discoloration of the donor region or expansion of ecchymosis to an adjacent anatomic regions beyond a zone of adherence. Although any complication documented in the medical record was recorded, only fat necrosis was found in greater than two patients. Fat necrosis diagnosed by clinical exam alone, was differentiated from additional cases of fat necrosis identified with imaging (mammography, ultrasound, or MRI). Follow-up time was measured in days from the date of fat grafting procedure to the last clinic visit. Outcome measures of interest included fat necrosis, ecchymosis overlying the region of fat harvest, and any adverse events such as deep vein thrombosis (DVT).

\section{Liposuction and Fat Grafting Technique}

Most of the fat grafting procedures were performed at the time of scar revision, minor contour revisions of the flap, or nipple reconstruction. General anesthesia was utilized for all patients. Tissues were infiltrated $15 \mathrm{~min}$ prior to harvest utilizing the "super wet" technique with a wetting solution consisting of lactated ringers combined with $15 \mathrm{ml}$ of $1 \%$ lidocaine, and 1 ampule of 1:1000 epinephrine per liter [51]. Cannula sizes from 3-4 mm were used according to the donor site. The donor site was selected based on physical exam confirmation of adequate adipose tissue and patient preference. TLT was performed with the HydraSolve Lipoplasty System (Andrew Technologies, Irvine, 
CA) in all cases. The device phaser stream was heated to $120-130^{\circ} \mathrm{F}$ and a pressure of $900-1100$ psi. Harvested fat was separated exclusively with subsequent gravity filtration in a large sterilized Wells-Johnson (Tuscon, AZ) canister for $\geq 10$ min with no further centrifugation. The infranatant aqueous layer was poured off and the supernatant fat transferred into syringes for reinjection in $0.1-1.0 \mathrm{cc}$ aliquots. Fat was injected into areas of contour irregularity and implant visibility usually in the superior and medial aspect of the reconstructed breast.

\section{Statistical Analysis}

None of the continuous variables were normally distributed, and so medians with interquartile ranges were reported. Descriptive statistics were calculated for demographic and clinical characteristics. Categorical variables were compared using a Pearson's Chi-squared test. Adjusted odds ratios and $95 \%$ confidence intervals were calculated for each independent variable for logistic regression analysis. A patient-level logistic regression was done to evaluate the association between fat necrosis and age, BMI, smoking status, diabetes mellitus, and hypertension. A breast-level logistic regression was performed to evaluate the association between fat necrosis and reconstruction type, fat donor area, fat graft volume, radiation, and the existence of tumor. Another logistic regression was performed to study the relationship between widespread ecchymosis of the donor area in patients with variables such as age, BMI, tumescence volume, fat graft volume, and duration of surgery. Statistical significance was set at a $p$ value of $<0.05$. Statistical analyses were performed using SPSS 23 software (IBM, Armonk, NY).

\section{Results}

\section{Patient Characteristics}

TLT was performed by two plastic surgeons (T.M.M. \& M.M.T) to harvest fat grafts as a method to revise breast reconstruction in 136 consecutive patients over a two-year period. Summarized in Table 1, the median age of the patients was 48 years old and median BMI was $26.8 \mathrm{~kg} /$ $\mathrm{m}^{2}$. There were only 2 current smokers among all patients. Fifty-eight patients $(24.5 \%)$ received radiotherapy prior to fat grafting. In 179 breasts $(75.5 \%)$ fat was injected around the implant and in 58 breasts $(24.5 \%)$ into autologous flaps. Among autologous flaps $67.2 \%(n=39)$ were DIEP flaps, $15.5 \%(n=9)$ were latissimus flaps, and $10.3 \%(n=6)$ were free TRAM flaps. The abdomen was utilized as the donor site for fat grafts in $48.5 \%$ of cases, followed by the flanks $(28.7 \%)$ or a combination of the flanks, abdomen, thigh, and bra strap roll (22.8\%). Median volume of the tumescence solution used per patient was $1500 \mathrm{ml}$. Median volume of fat graft injected per breast was $90 \mathrm{ml}$. Median duration of procedures where fat transfers were performed with TLT was 79 min. Importantly, fat transfer was combined with other reconstructive procedures to revise the reconstructed breast or improve symmetry of the contralateral side $94.1 \%$ of the time. Implant exchange $(66.5 \%)$, nipple reconstruction $(27.1 \%)$, and a contralateral augmentation, mastopexy, or reduction $(18.7 \%)$ were the most common accompanying procedures and contributed to the duration of the procedure as they were usually being concomitantly performed. Median follow-up after fat transfer was 143 days.

\section{Complications}

Among 136 patients, 97 (71.1\%) had minimal donor site ecchymosis. Twelve $(8.8 \%)$ patients were noted to have fat necrosis by clinical exam, while an additional 18 $(13.3 \%)$ were considered to have fat necrosis based on review of additional breast imaging studies for a total of 30 $(22.1 \%$ ) patients (Table 2). Among 237 breasts, fat necrosis was found in 31 breasts $(13.1 \%)$ but was clinically evident in only $15(6.3 \%)$. There were no incidents of cellulitis, hematoma, or wound dehiscence at the donor site where TLL was performed. At the recipient site, complications were rare but included hematoma requiring evacuation $(n=2)$, cellulitis $(n=2)$, and wound dehiscence $(n=2)$. A single DVT occurred without progression to pulmonary embolism. There was no statistically significant difference between patients who did and did not experience fat necrosis according to age, BMI, comorbidities, smoking status, history of radiotherapy, reconstruction type, liposuction region, tumescence volume, fat graft volume, and operation duration (Table 1). Patients who had fat necrosis had significantly longer follow-up than patients who did not (198 vs. 135 days, $p=0.005$ ).

Logistic regression analysis of all patient cohorts ( $n=136)$ found no statistically significant relationship between fat necrosis and the variables seen in Fig. 1. Another logistic regression analysis in breasts $(n=237)$ found no statistically significant relationship between fat necrosis and reconstruction type, donor site, fat graft volume, radiotherapy, and history of tumor with previous therapeutic versus prophylactic mastectomy (Fig. 2). Minimal donor site ecchymosis was noted in $71.1 \%$ of patients $(n=96)$, moderate ecchymosis in $18.5 \%$ $(n=25)$, and widespread ecchymosis in only $10.4 \%$ $(n=14)$. A logistic regression analysis performed in this patient cohort $(n=136)$ found that among variables 
Table 1 Demographic and clinical characteristics organized by development of fat necrosis

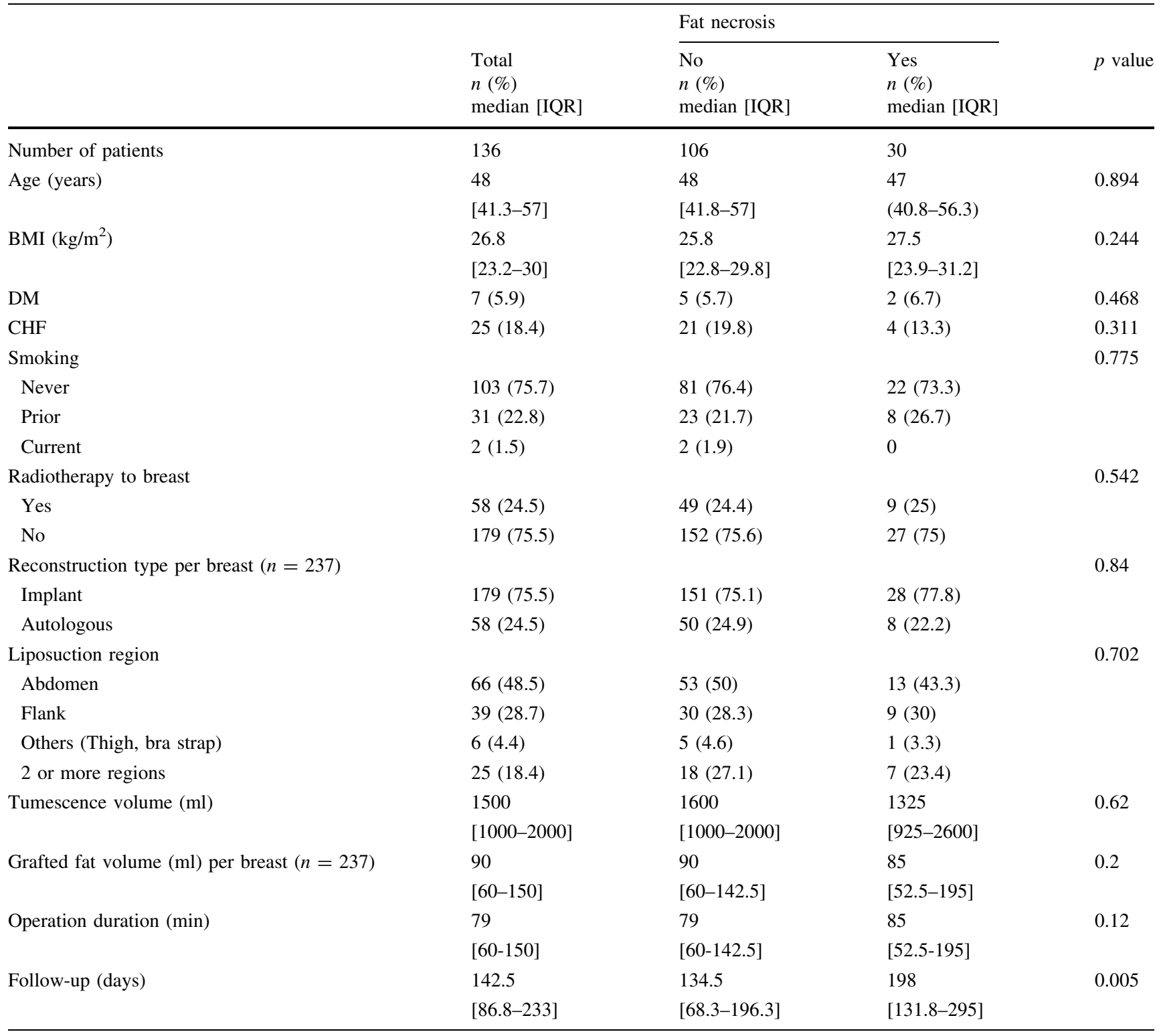

Table 2 Fat transfer complications at the recipient site when using tissue liquefaction technology (TLT) for graft harvest

\begin{tabular}{lc}
\hline Complications & \\
\hline Fat necrosis & \\
$\quad$ Clinically exam only & $12(8.8 \%)$ \\
Clinical exam + imaging (MRI/ultrasound) & $30(22.1 \%)$ \\
Hematoma & $2(1.5)$ \\
Cellulitis & $2(1.5)$ \\
Wound dehiscence & $2(1.5)$ \\
Pain & $2(1.5)$ \\
DVT & $1(0.6)$ \\
No & $97(71.3)$ \\
\hline
\end{tabular}

No complications were noted at the donor site documented in Fig. 3, only BMI over $30 \mathrm{~kg} / \mathrm{m}^{2}$ had a significant impact $(p=0.04)$, decreasing the odds ratio of widespread ecchymosis by 0.10 (95\% CI $0.01-0.87$ ).

\section{Discussion}

This study shows our early two-surgeon experience when TLL was used to harvest adipocytes for transfer to achieve contour correction in women having undergone prosthetic or autologous breast reconstruction. Over a 2-year period, TLL was safely used to harvest adipocytes for fat grafting to the reconstructed breast in 136 consecutive cases. The only significant systemic adverse event was a single case of 


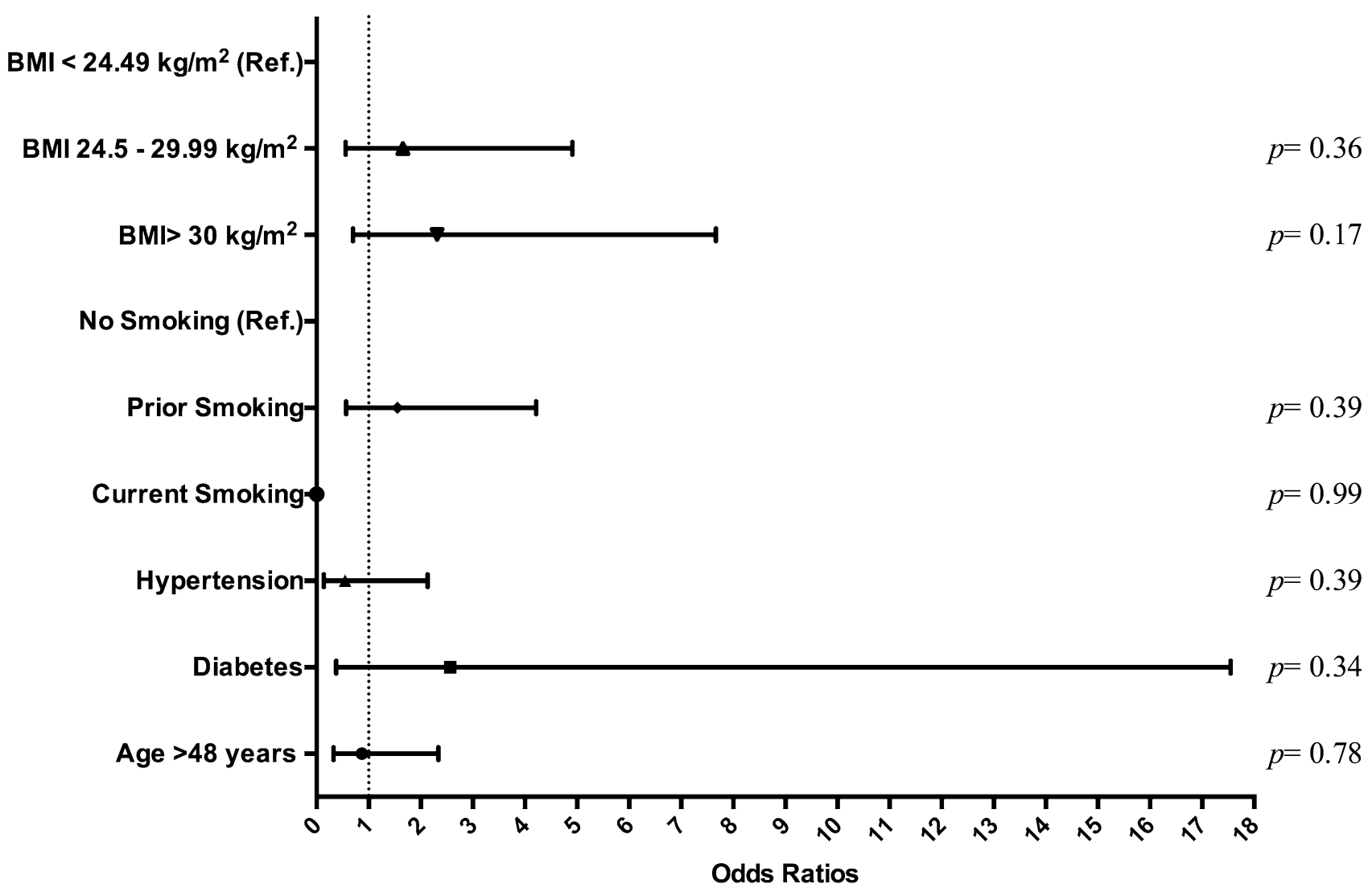

Fig. 1 Regression analysis of fat necrosis adjusted to diabetes mellitus, hypertension, age, smoking status, and BMI stratification by patient $(n=136)$

Fig. 2 Regression analysis of fat necrosis adjusted to breast reconstruction method, fat donor region, volume of fat graft, and radiotherapy by breast $(n=237)$

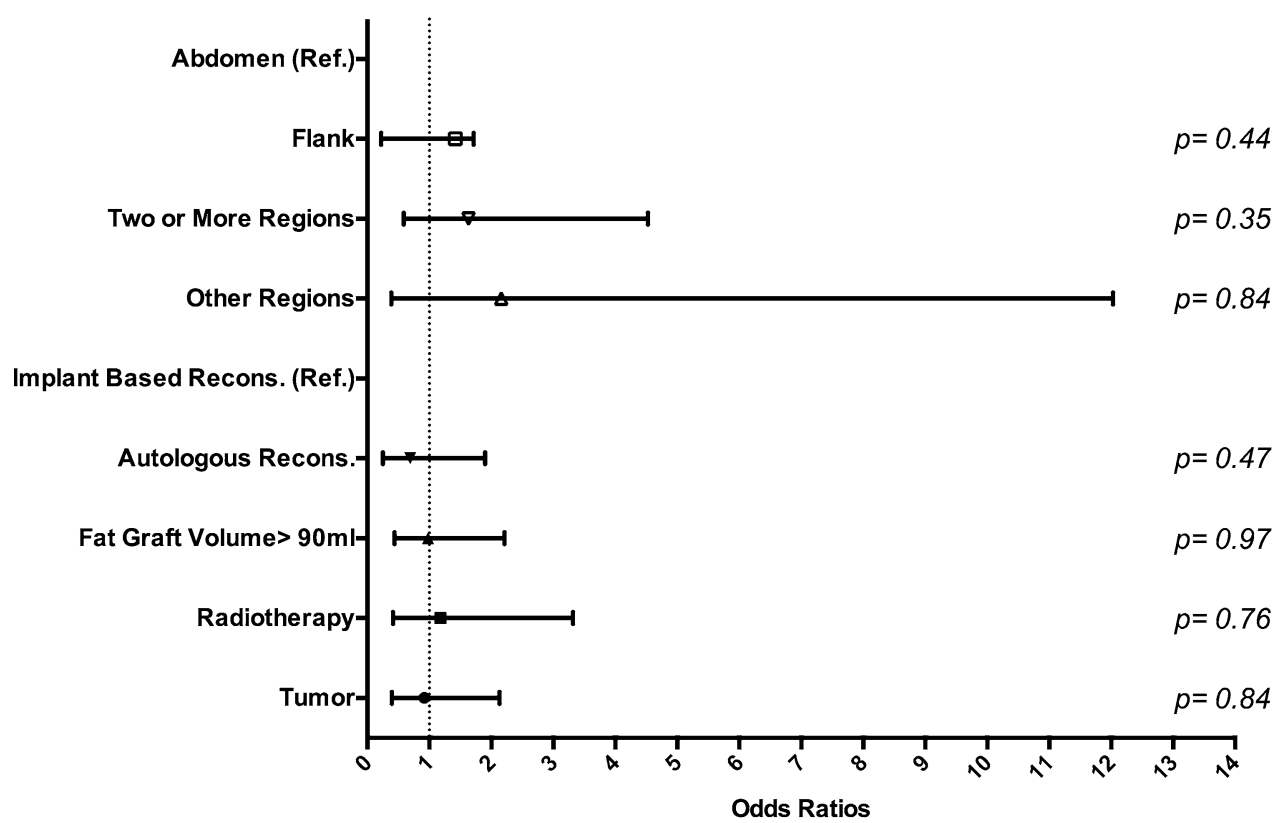

DVT $(0.74 \%)$ without pulmonary embolism. Consistent with our findings, in the liposuction population, venous thromboembolic events (VTE) occur in $0-1.1 \%$ of the large volume liposuction cases [3, 6, 19] According to the
National Surgical Quality Improvement Program (NSQIP) database, patients who have undergone mastectomy with immediate reconstruction will experience a DVT within 30 days in $0.41-0.52 \%$ of cases, [36] and later DVTs are 


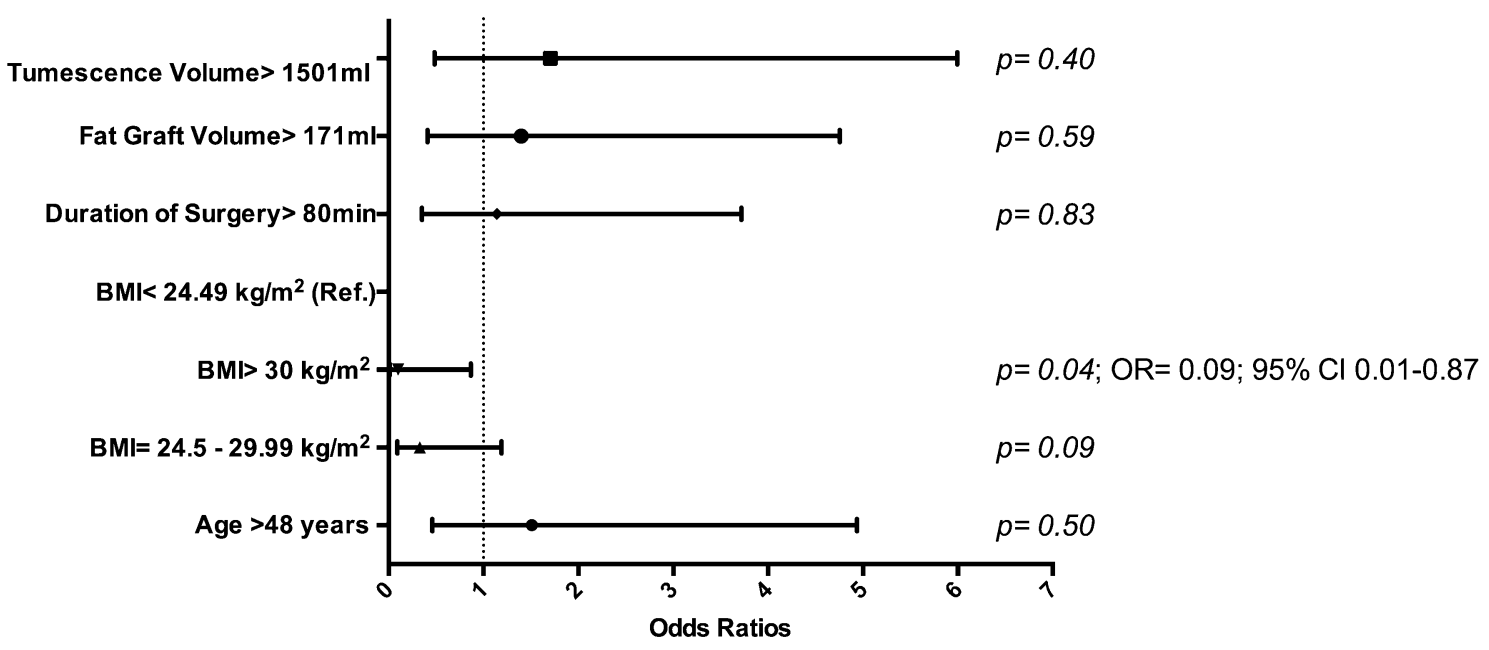

Fig. 3 Regression analysis of severe ecchymosis of donor area adjusted to age, BMI, tumescence volume, fat graft volume, and duration of surgery in patients $(n=136)$

unsettlingly frequent in patients with a former malignancy, even after tumor resection [1]. Fat transfer was often combined with other breast reconstruction revisions including nipple reconstruction, capsulorrhaphy, or a contralateral breast augmentation, reduction, or mastopexy to improve symmetry. While we are unaware of any data to suggest that combining fat transfer with other reconstructive breast procedures increases VTE events, there is strong evidence in the aesthetic surgery literature to suggest that performing concurrent procedures increases the risk of VTE complications [4, 21, 58].

There were no significant donor site-associated complications in this series. None of the patients developed a hematoma requiring evacuation or cellulitis at their donor sites and $71.1 \%$ exhibited only minimal ecchymosis. We concede that the degree of ecchymosis is prone to interpretation, particularly in a retrospective review. Still, the degree of ecchymosis identified in our series is consistent with that reported by a prospective randomized control trial that found "less" ecchymosis following both suction- and laser-assisted lipoplasty [45]. Interestingly, obesity significantly reduced the risk of developing widespread ecchymosis in our study. We doubt that an elevated BMI has a protective effect on bleeding caused by TLL. Rather, any minor bleeding caused by TLL is more readily concealed in the larger volume of adipose tissue that would commonly characterize an individual with a higher BMI.

Cellulitis, hematoma, and incisional dehiscence all occurred at a rate of $<2 \%$ at the recipient site and were not attributable to TLL. We identified fat necrosis in $22.1 \%$ of patients by clinical exam or imaging. Fat necrosis, or downstream sequela-like oil cysts and microcalcifications which were included as fat necrosis events in this series, are known to occur in 3.9 [62] to $47 \%$ of patients [18], with a recent review reporting mammographic evidence of clear cystic lesions in $25 \%$ of patients receiving fat transfer to the breast in a mixed cohort of aesthetic and reconstructive cases [57]. We recognize that the incidence of fat necrosis identified by our study is subject to criticism, and even when diagnosed by imaging, may be dependent on the modality utilized. For example, while microcalcifications were identified by mammography in $19 \%$ of patients in one series, cystic lesions were identified in $47 \%$ of these patients by magnetic resonance imaging [18]. Our data are relatively consistent with these reports noting that we found clinical evidence of fat necrosis in $8.8 \%$ of patients, or $6.3 \%$ of breasts, with a substantial increase in sensitivity for this finding afforded by further imaging. Our data are consistent with other reports suggesting that the harder you look for fat necrosis with multimodality imaging, the more likely you are to find it $[7,18]$. The clinical impact of fat necrosis in this study was modest, as only $4(2.9 \%)$ patients required operative excision-two to rule out malignancy and two to address uncomfortable induration. There was also a correlation between the recognition of fat necrosis and longer followup $(p=0.005)$. This may be due to a combination of factors like a greater number of opportunities for clinical and radiographic surveillance, as well as uncovering areas of fat necrosis previously concealed by surrounding swelling. Interestingly, we did not find a higher rate of fat necrosis with increasing volumes of fat transferred. Safe transfer of larger volumes of fat may be attributable to careful preparation of the recipient space [26].

Suction-, ultrasound-, and water jet-assisted liposuction are current methods for fat transfer, and each is supported by several studies examining their impact on harvested adipocyte viability [2]. Compared to en bloc resected fat, adipocytes harvested with SAL possess proportionately fewer adipose-derived stem cells, but those harvested without SAL 
possess similar viability and differentiation characterization [12]. This detailed analysis by Duscher et al. verifies that SAL is an effective method of fat harvest for cell-based therapies [12]. Ultrasound-assisted suction lipectomy (UAL) initiates the rapid rarefaction and compression of tumescence fluid bubbles-lodged between adipocytes-to resonant size. Adipocytes are dislodged by these rapidly enlarging fluid bubbles (stable cavitation) and then dispersed with the tumescence solution via acoustic streaming [47]. A lipolysis assay of fat harvested using UAL at an amplitude of $60 \%$ suggested that $85.1 \%$ of harvested adipocytes were viable and metabolically active [47]. Propidium iodide staining, an alternative methodology, suggested that $88.7 \%$ of adipocytes were viable, while previous work suggests that UAL does not adversely impact the proliferative or osteogenic capacity of adipose-derived stem cells [40]. An elegant series of experiments recently demonstrates that lipoaspirates harvested with UAL and SAL share a similar proportion of viable adipose-derived stem cells with equivalent expression of regenerative genes and potential to differentiate into chondrocytes, adipocytes, or osteocytes [11]. Another technology, water jet-assisted liposuction (WAL) uses a dual-aperture cannula that simultaneously emits tumescence solution as a fan-shaped, pulsating jet through an anteriorly located aperture, and suction fluid and aspirated fat from a more posteriorly located side port [35, 46, 59]. Human fat harvested with WAL demonstrated greater viability using both colorimetric and glucose transport test assays, with greater retention by weight, less apoptosis by Annexin V expression, and increased revascularization by CD31 immunostaining when injected as a xenograft into a murine host [59]. Other work has suggested that fat harvested with WAL contains abundant CD34+ cells suggesting a stem cell-rich stromal vascular fraction although a control group was not utilized in this study [35]. Although human data are not available, rats engrafted with human adipose xenografts harvested with TLL demonstrate adipocyte viability, graft weight, and histology comparable to the Coleman technique [9]. To truly compare the efficacy of one of these techniques over another, a single study that utilizes the same outcome metrics and units of measure is required. In addition, while optimized fat graft retention relies, at least in part, on the viability of harvested adipocytes [52], the maintenance of volume correction conferred by fat transfer likely also relies on fibrotic ingrowth and ghost cells [20].

Practical considerations like efficiency and cost effectiveness accompany the ability of a liposuction device to harvest adipocytes for fat transfer. Harvested fat can be prepared in several ways including centrifugation, gauze rolling, gravity separation, or proprietary fat processing devices [5, 29]. Large volume fat transfers, in particular, can be time consuming and potentially tedious. In a recent study that compared the Revolve ${ }^{\mathrm{TM}}$ (Acelity, NJ) fat processing device to the Coleman technique, the additional consumable cost of the Revolve ${ }^{\mathrm{TM}}$ device was felt to be economically justified for planned transfers greater than $75 \mathrm{cc}$ and operative times were noted to be 10-20 min shorter [5]. In our series, fat harvested with TLT was collected in a large, reusable, sterilized canister and subjected to gravity filtration for at least $10 \mathrm{~min}$. Fat transfer was accompanied by concurrent revision procedures $94.1 \%$ of the time in our study and yet the median total operative time was 79 min with an interquartile range of 60-150 $\mathrm{min}$. As such, the "downtime" that may have occurred waiting for gravity filtration to occur was actually occupied by other revision procedures. In addition, recognizing that these ancillary procedures included implant exchanges, nipple reconstructions, and in many cases, breast reductions, augmentation, or mastopexies, we felt that the incorporation of TLT with gravity filtration into our fat transfer regimen was suitably efficient. After discarding the aqueous infranatant, we transferred a median of $90 \mathrm{cc}$ of adipose tissue per breast, and were able to do this without any other processing step. Moreover, adipocytes were suctioned in a closed system directly into a canister and then collected into syringes leading to fewer opportunities for bacterial contamination and loss of harvested fat due to leakage or spills.

This series is the first to report on the use of TLT for fat transfer but further work will establish its value as an addition to the liposuction and fat transfer device armamentarium. This study is subject to the inherent weaknesses of a retrospective review, and in particular the ability to precisely quantify the degree of ecchymosis, fat necrosis, graft retention, and patient satisfaction. Balancing the efficiencies and outcomes derived from using this technology versus the capital and consumable costs of this device requires a formal cost analysis. Moreover, our study lacks a control group that keeps other variables constant and employs a technique like standard suction-assisted lipectomy to compare to TLT. The viability of adipocytes, characteristics of the stromal vascular fraction, and degree and long-term durability of contour correction using fat harvested by TLT should be directly compared to an SAL control group as well as other harvesting technologies like WAL and UAL. A real-world cost analysis rather than application of a theoretical model to evaluate direct hospital costs and physician reimbursement when using TLT versus other technologies would also be of value.

\section{Conclusions}

We present the first experience with TLL to harvest adipocytes for fat transfer in postmastectomy breast reconstruction revision. TLL was well tolerated with a low 
incidence of donor site ecchymosis and fat necrosis rates consistent with other fat harvest techniques. In addition to aesthetic liposuction, TLL represents a viable option to harvest fat for lipofilling in breast reconstruction.

\section{Compliance with Ethical Standards}

Disclosure TM and MT have received consulting fees from Andrew Technologies in the last year. This company manufactures the HydraSolve device. However, no funds were received to conduct this study nor is this company privy to any of the study results.

\section{References}

1. Agnelli G, Bolis G, Capussotti L, Scarpa RM, Tonelli F, Bonizzoni E, Moia M, Parazzini F, Rossi R, Sonaglia F, Valarani B, Bianchini C, Gussoni G (2006) A clinical outcome-based prospective study on venous thromboembolism after cancer surgery: the @RISTOS project. Ann Surg 243(1):89-95

2. Ahmad J, Eaves FF 3rd, Rohrich RJ, Kenkel JM (2011) The American Society for Aesthetic Plastic Surgery (ASAPS) survey: current trends in liposuction. Aesthet Surg J 31(2):214-224

3. Albin R, de Campo T (1999) Large-volume liposuction in 181 patients. Aesthet Plast Surg 23(1):5-15

4. Aly AS, Cram AE, Chao M, Pang J, McKeon M (2003) Belt lipectomy for circumferential truncal excess: the university of iowa experience. Plast Reconstr Surg 111(1):398-413

5. Brzezienski MA, Jarrell JA (2015) Autologous fat grafting to the breast using REVOLVE system to reduce clinical costs. Ann Plast Surg. doi:10.1097/SAP.0000000000000590

6. Commons GW, Halperin B, Chang CC (2001) Large-volume liposuction: a review of 631 consecutive cases over 12 years. Plast Reconstr Surg 108(6):1753-1763

7. Costantini M, Cipriani A, Belli P, Bufi E, Fubelli R, Visconti G, Salgarello M, Bonomo L (2013) Radiological findings in mammary autologous fat injections: a multi-technique evaluation. Clin Radiol 68(1):27-33

8. Crawford JL, Hubbard BA, Colbert SH, Puckett CL (2010) Fine tuning lipoaspirate viability for fat grafting. Plast Reconstr Surg 126(4):1342-1348

9. Davis K, Rasko Y, Oni G, Bills J, Geissler P, Kenkel JM (2013) Comparison of adipocyte viability and fat graft survival in an animal model using a new tissue liquefaction liposuction device vs standard coleman method for harvesting. Aesthet Surg J 33(8):1175-1185

10. Direkze NC, Jeffery R, Hodivala-Dilke K, Hunt T, Playford RJ, Elia G, Poulsom R, Wright NA, Alison MR (2006) Bone marrowderived stromal cells express lineage-related messenger RNA species. Cancer Res 66(3):1265-1269

11. Duscher D, Atashroo D, Maan ZN, Luan A, Brett EA, Barrera J, Khong SM, Zielins ER, Whittam AJ, Hu MS, Walmsley GG, Pollhammer MS, Schmidt M, Schilling AF, Machens HG, Huemer GM, Wan DC, Longaker MT, Gurtner GC (2016) Ultrasound-assisted liposuction does not compromise the regenerative potential of adipose-derived stem cells. Stem Cells Transl Med $5(2): 248-257$

12. Duscher D, Luan A, Rennert RC, Atashroo D, Maan ZN, Brett EA, Whittam AJ, Ho N, Lin M, Hu MS, Walmsley GG, Wenny R, Schmidt M, Schilling AF, Machens HG, Huemer GM, Wan DC, Longaker MT, Gurtner GC (2016) Suction assisted liposuction does not impair the regenerative potential of adipose derived stem cells. J Transl Med 14(1):126
13. Erdim M, Tezel E, Numanoglu A, Sav A (2009) The effects of the size of liposuction cannula on adipocyte survival and the optimum temperature for fat graft storage: an experimental study. J Plast Reconstr Aesthet Surg 62(9):1210-1214

14. Fabi SG, Goldman MP (2012) Hand rejuvenation: a review and our experience. Dermatol Surg 38(7 Pt 2):1112-1127

15. Fulton JE Jr, Rahimi AD, Helton P, Watson T, Dahlberg K (2000) Lip rejuvenation. Dermatol Surg 26(5):470-474

16. Gale KL, Rakha EA, Ball G, Tan VK, McCulley SJ, Macmillan $\mathrm{RD}$ (2015) A case-controlled study of the oncologic safety of fat grafting. Plast Reconstr Surg 135(5):1263-1275

17. Girard AC, Atlan M, Bencharif K, Gunasekaran MK, Delarue P, Hulard O, Lefebvre-d'Hellencourt C, Roche R, Hoareau L, Festy F (2013) New insights into lidocaine and adrenaline effects on human adipose stem cells. Aesthet Plast Surg 37(1):144-152

18. Gosset J, Guerin N, Toussoun G, Delaporte T, Delay E (2008) Radiological evaluation after lipomodelling for correction of breast conservative treatment sequelae. Ann Chir Plast Esthet 53(2): 178-189

19. Grazer FM, de Jong RH (2000) Fatal outcomes from liposuction: census survey of cosmetic surgeons. Plast Reconstr Surg 105(1):436-446

20. Harrison BL, Malafa M, Davis K, Rohrich RJ (2015) The discordant histology of grafted fat: a systematic review of the literature. Plast Reconstr Surg 135(3):542e-555e

21. Hester TR Jr, Baird W, Bostwick J 3rd, Nahai F, Cukic J (1989) Abdominoplasty combined with other major surgical procedures: safe or sorry? Plast Reconstr Surg 83(6):997-1004

22. Hivernaud V, Lefourn B, Guicheux J, Weiss P, Festy F, Girard AC, Roche R (2015) Autologous fat grafting in the breast: critical points and technique improvements. Aesthet Plast Surg 39(4):547-561

23. Iyengar P, Espina V, Williams TW, Lin Y, Berry D, Jelicks LA, Lee H, Temple K, Graves R, Pollard J, Chopra N, Russell RG, Sasisekharan R, Trock BJ, Lippman M, Calvert VS, Petricoin EF 3rd, Liotta L, Dadachova E, Pestell RG, Lisanti MP, Bonaldo P, Scherer PE (2005) Adipocyte-derived collagen VI affects early mammary tumor progression in vivo, demonstrating a critical interaction in the tumor/stroma microenvironment. J Clin Invest 115(5):1163-1176

24. Keck M, Kober J, Riedl O, Kitzinger HB, Wolf S, Stulnig TM, Zeyda M, Gugerell A (2014) Power assisted liposuction to obtain adipose-derived stem cells: impact on viability and differentiation to adipocytes in comparison to manual aspiration. J Plast Reconstr Aesthet Surg 67(1):e1-e8

25. Keck M, Zeyda M, Gollinger K, Burjak S, Kamolz LP, Frey M, Stulnig TM (2010) Local anesthetics have a major impact on viability of preadipocytes and their differentiation into adipocytes. Plast Reconstr Surg 126(5):1500-1505

26. Khouri RK, Rigotti G, Cardoso E, Khouri RK Jr, Biggs TM (2014) Megavolume autologous fat transfer: part I theory and principles. Plast Reconstr Surg 133(3):550-557

27. Khouri RK, Rigotti G, Cardoso E, Khouri RK Jr, Biggs TM (2014) Megavolume autologous fat transfer: part II Practice and techniques. Plast Reconstr Surg 133(6):1369-1377

28. Khouri RK, Smit JM, Cardoso E, Pallua N, Lantieri L, Mathijssen IM, Khouri RK Jr, Rigotti G (2013) Percutaneous aponeurotomy and lipofilling: a regenerative alternative to flap reconstruction? Plast Reconstr Surg 132(5):1280-1290

29. Kling RE, Mehrara BJ, Pusic AL, Young VL, Hume KM, Crotty CA, Rubin JP (2013) Trends in autologous fat grafting to the breast: a national survey of the american society of plastic surgeons. Plast Reconstr Surg 132(1):35-46

30. Klinger M, Caviggioli F, Klinger FM, Giannasi S, Bandi V, Banzatti B, Forcellini D, Maione L, Catania B, Vinci V (2013) 
Autologous fat graft in scar treatment. J Craniofac Surg 24(5):1610-1615

31. Largo RD, Tchang LA, Mele V, Scherberich A, Harder Y, Wettstein R, Schaefer DJ (2014) Efficacy, safety and complications of autologous fat grafting to healthy breast tissue: a systematic review. J Plast Reconstr Aesthet Surg 67(4):437-448

32. Lohsiriwat V, Curigliano G, Rietjens M, Goldhirsch A, Petit JY (2011) Autologous fat transplantation in patients with breast cancer: "silencing" or "fueling" cancer recurrence? Breast 20(4):351-357

33. Manabe Y, Toda S, Miyazaki K, Sugihara H (2003) Mature adipocytes, but not preadipocytes, promote the growth of breast carcinoma cells in collagen gel matrix culture through cancerstromal cell interactions. J Pathol 201(2):221-228

34. Martin-Padura I, Gregato G, Marighetti P, Mancuso P, Calleri A, Corsini C, Pruneri G, Manzotti M, Lohsiriwat V, Rietjens M, Petit JY, Bertolini F (2012) The white adipose tissue used in lipotransfer procedures is a rich reservoir of CD34+ progenitors able to promote cancer progression. Cancer Res 72(1):325-334

35. Meyer J, Salamon A, Herzmann N, Adam S, Kleine HD, Matthiesen I, Ueberreiter K, Peters K (2015) Isolation and differentiation potential of human mesenchymal stem cells from adipose tissue harvested by water jet-assisted liposuction. Aesthet Surg J 35(8):1030-1039

36. Nwaogu I, Yan Y, Margenthaler JA, Myckatyn TM (2015) Venous thromboembolism after breast reconstruction in patients undergoing breast surgery: an american college of surgeons NSQIP analysis. J Am Coll Surg 220(5):886-893

37. Orecchioni S, Gregato G, Martin-Padura I, Reggiani F, Braidotti P, Mancuso P, Calleri A, Quarna J, Marighetti P, Aldeni C, Pruneri G, Martella S, Manconi A, Petit JY, Rietjens M, Bertolini F (2013) Complementary populations of human adipose CD34+ progenitor cells promote growth, angiogenesis, and metastasis of breast cancer. Cancer Res 73(19):5880-5891

38. Ozsoy Z, Kul Z, Bilir A (2006) The role of cannula diameter in improved adipocyte viability: a quantitative analysis. Aesthet Surg J 26(3):287-289

39. Padoin AV, Braga-Silva J, Martins P, Rezende K, Rezende AR, Grechi B, Gehlen D, Machado DC (2008) Sources of processed lipoaspirate cells: influence of donor site on cell concentration. Plast Reconstr Surg 122(2):614-618

40. Panetta NJ, Gupta DM, Kwan MD, Wan DC, Commons GW, Longaker MT (2009) Tissue harvest by means of suction-assisted or third-generation ultrasound-assisted lipoaspiration has no effect on osteogenic potential of human adipose-derived stromal cells. Plast Reconstr Surg 124(1):65-73

41. Panfilov DE (2006) Augmentative phalloplasty. Aesthet Plast Surg 30(2):183-197

42. Petit JY, Botteri E, Lohsiriwat V, Rietjens M, De Lorenzi F, Garusi C, Rossetto F, Martella S, Manconi A, Bertolini F, Curigliano G, Veronesi P, Santillo B, Rotmensz N (2012) Locoregional recurrence risk after lipofilling in breast cancer patients. Ann Oncol 23(3):582-588

43. Petit JY, Lohsiriwat V, Clough KB, Sarfati I, Ihrai T, Rietjens M, Veronesi P, Rossetto F, Scevola A, Delay E (2011) The oncologic outcome and immediate surgical complications of lipofilling in breast cancer patients: a multicenter study-milan-paris-lyon experience of 646 lipofilling procedures. Plast Reconstr Surg 128(2):341-346

44. Petit JY, Rietjens M, Botteri E, Rotmensz N, Bertolini F, Curigliano G, Rey P, Garusi C, De Lorenzi F, Martella S, Manconi A, Barbieri B, Veronesi P, Intra M, Brambullo T, Gottardi A, Sommario M, Lomeo G, Iera M, Giovinazzo V, Lohsiriwat V (2013) Evaluation of fat grafting safety in patients with intraepithelial neoplasia: a matched-cohort study. Ann Oncol 24(6):1479-1484
45. Prado A, Andrades P, Danilla S, Leniz P, Castillo P, Gaete F (2006) A prospective, randomized, double-blind, controlled clinical trial comparing laser-assisted lipoplasty with suction-assisted lipoplasty. Plast Reconstr Surg 118(4):1032-1045

46. Sasaki GH (2011) Water-assisted liposuction for body contouring and lipoharvesting: safety and efficacy in 41 consecutive patients. Aesthet Surg J 31(1):76-88

47. Schafer ME, Hicok KC, Mills DC, Cohen SR, Chao JJ (2013) Acute adipocyte viability after third-generation ultrasound-assisted liposuction. Aesthet Surg J 33(5):698-704

48. Schaffler A, Scholmerich J, Buechler C (2007) Mechanisms of disease: adipokines and breast cancer-endocrine and paracrine mechanisms that connect adiposity and breast cancer. Nat Clin Pract Endocrinol Metab 3(4):345-354

49. Shiffman MA, Mirrafati S (2001) Fat transfer techniques: the effect of harvest and transfer methods on adipocyte viability and review of the literature. Dermatol Surg 27(9):819-826

50. Sinno S, Mehta K, Reavey PL, Simmons C, Stuzin JM (2015) Current trends in facial rejuvenation: an assessment of asps members' use of fat grafting during face lifting. Plast Reconstr Surg 136(1):20e-30e

51. Stephan PJ, Kenkel JM (2010) Updates and advances in liposuction. Aesthet Surg J 30(1):83-97

52. Strong AL, Cederna PS, Rubin JP, Coleman SR, Levi B (2015) The current state of fat grafting: a review of harvesting, processing, and injection techniques. Plast Reconstr Surg 136(4):897-912

53. Sultan SM, Stern CS, Allen RJ Jr, Thanik VD, Chang CC, Nguyen PD, Canizares O, Szpalski C, Saadeh PB, Warren SM, Coleman SR, Hazen A (2011) Human fat grafting alleviates radiation skin damage in a murine model. Plast Reconstr Surg 128(2):363-372

54. Surgeons A. S. o. P. (2013).2012 Plastic surgery statistics report ASPS national clearinghouse of plastic surgery procedural statistics

55. Toledo LS (2015) Gluteal augmentation with fat grafting: The Brazilian Buttock technique: 30 years' experience. Clin Plast Surg 42(2):253-261

56. Ullmann Y, Shoshani O, Fodor A, Ramon Y, Carmi N, Eldor L, Gilhar A (2005) Searching for the favorable donor site for fat injection: in vivo study using the nude mice model. Dermatol Surg 31(10):1304-1307

57. Veber M, Tourasse C, Toussoun G, Moutran M, Mojallal A, Delay E (2011) Radiographic findings after breast augmentation by autologous fat transfer. Plast Reconstr Surg 127(3):1289-1299

58. Voss SC, Sharp HC, Scott JR (1986) Abdominoplasty combined with gynecologic surgical procedures. Obstet Gynecol 67(2):181-185

59. Yin S, Luan J, Fu S, Wang Q, Zhuang Q (2015) Does water-jet force make a difference in fat grafting? In vitro and in vivo evidence of improved lipoaspirate viability and fat graft survival. Plast Reconstr Surg 135(1):127-138

60. Zhang Y, Daquinag A, Traktuev DO, Amaya-Manzanares F, Simmons PJ, March KL, Pasqualini R, Arap W, Kolonin MG (2009) White adipose tissue cells are recruited by experimental tumors and promote cancer progression in mouse models. Cancer Res 69(12):5259-5266

61. Zimmerlin L, Donnenberg AD, Rubin JP, Basse P, Landreneau RJ, Donnenberg VS (2011) Regenerative therapy and cancer: in vitro and in vivo studies of the interaction between adiposederived stem cells and breast cancer cells from clinical isolates. Tissue Eng Part A 17(1-2):93-106

62. Zocchi ML, Zuliani F (2008) Bicompartmental breast lipostructuring. Aesthet Plast Surg 32(2):313-328 